\title{
The history of psychiatry: personal reflections
}

\author{
A Beveridge \\ Consultant Psychiatrist, Queen Margaret Hospital, Dunfermline, Scotland
}

\begin{abstract}
Does an engagement with the history of psychiatry benefit the practising clinician? This paper adopts a personal perspective. It sketches the ideological conflicts which have raged in the study of the history of psychiatry in recent decades and looks at the often heated debates between historians and psychiatrists on the subject. It looks at the author's involvement with the subject and considers how this may have influenced both clinical practice and the approach to history. The paper then considers the author's work in the field and the interplay between historical theory and clinical practice. It concludes that studying the history of their subject can make doctors more reflective about their work.
\end{abstract}

\author{
Correspondence to A Beveridge \\ Queen Margaret Hospital \\ Whitefield Road \\ Dunfermline \\ KYI2 OSU \\ e-mail allanbeveridge@nhs.net
}

KEYWORDS History, psychiatry, practice, case note studies, patient perspective, biography

DECLARATIONS OF INTERESTS No conflicts of interest declared.

\section{INTRODUCTION}

The question of whether a knowledge of medical history makes for better doctors has long been debated. Warner' has queried its potential to make clinicians more humane and, instead, suggests that an engagement with the subject looks both inward, offering the individual student a source of reflection on his or her own professional formation, and outward, offering a forum for discussing how values, prejudices and inequalities came to be built into the current medical enterprise taking nothing for granted'. In this paper I will examine how the study of the history of psychiatry has influenced my work as a psychiatrist. I will sketch the recent development of the discipline of the history of psychiatry, before looking at how my own research in the field has affected my approach to clinical work.

\section{THE HISTORY OF THE HISTORY OF PSYCHIATRY}

Until recent decades, the history of psychiatry was written mainly by psychiatrists. The tale they told was of benign progress: psychiatry was becoming progressively more humane as clinicians developed more and more effective treatments. This type of approach tended to adopt the 'Great Man' theory of history. Changes were seen as being brought about by the actions of eminent individuals and the wider social, cultural and political context was ignored. This kind of history was seen by non-medical people as complacent, self-congratulatory and serving to legitimise psychiatry's present.

This cosy view of psychiatry's past was challenged by those outside the psychiatric profession. The French philosopher Michel Foucault ${ }^{2}$ published Madness and Civilisation in 1961 (translated into English in 1965); his work overturned the story of benign progress, arguing that the 'mad' enjoyed comparative freedom until the advent of the Enlightenment in the eighteenth century which saw the birth of psychiatry. This led to what Foucault called 'the great confinement', which witnessed vast numbers of the mentally disturbed 'herded' into institutions. Foucault maintained that the voice of 'unreason' was silenced by the forces of 'reason', in the shape of the emerging lunacy profession. Further attacks on the benign version of psychiatry's past came in 1979 from Andrew Scull, ${ }^{3}$ an American sociologist whose Museums of Madness examined the rise of the asylum in nineteenth century Britain. Asylums, he argued, served as a 'convenient place to dump inconvenient people'. Asylum doctors were portrayed as doing the state's bidding in ridding society of its discontents and disaffected.

These self-styled 'revisionist' histories, which set out to challenge 'Whiggish' accounts of progress (progressive improvement over the years), stimulated a great deal of research, and an area which had previously been rather sleepy and dominated by clinicians became the battleground for a host of other disciplines - medical historians, philosophers, feminists, sociologists - who each brought their own interpretations to the table. Psychiatrists were stimulated to examine the claims of the revisionists and several looked at the records of Victorian asylums as a starting point. Who was admitted to these institutions? Were they the flotsam of society? Did they suffer from mental illness? Were psychiatric disorders really social constructs? Were female patients locked up because they breached the strict codes of the patriarchal society in which they lived? Were psychiatrists agents of social control or were they motivated by compassion? 
Historians were also stimulated by the new revisionist accounts, and there was an explosion of scholarly activity. The leading centre for this was the Wellcome History of Medicine Unit in London, where Roy Porter, William Bynum ${ }^{4}$ and others worked. A good example of their activity was the three volume collection of essays, The Anatomy of Madness, published in the mid 1980s, based on a series of seminars by an international group of scholars. The most prolific was Roy Porter, who emphasised seeing history from the patient's perspective. Styled 'history from below', this approach emphasised that we shouldn't just concentrate on official medical records, but rather look at what patients had to say about their experiences of illness and treatment. Porter also brought a sparkling prose style to the subject, which was both accessible and engaging.

A sign of the growing interest in the field was the First European Congress on the History of Psychiatry, held in 's-Hertogenbosch, Holland in October 1990. This brought together historians and psychiatrists from all over Europe. For a young psychiatrist, like myself, just starting to study the history of the discipline, this was an exciting event. The major figures in the area, Roy Porter, Andrew Scull, Klaus Doerner, William Parry-Jones and German Berrios all spoke. Young German scholars were beginning to research the Nazi period, a subject which had hitherto been avoided. Ethical and philosophical issues were confronted and there was a sense that the history of psychiatry was important: it wasn't just a dryas-dust, antiquarian activity, but something that raised fundamental questions about the nature of psychiatry and society's response to madness. A further sign of interest was the founding of the journal, History of Psychiatry in 1991. Significantly, it was edited by an historian, Roy Porter and a psychiatrist, German Berrios, and represented the belief that the two disciplines should work together and open up a dialogue rather than continue to conduct hostile exchanges.

\section{THE RELATION BETWEEN HISTORIANS AND PSYCHIATRISTS}

In Discovering the History of Psychiatry, Micale and Porter ${ }^{5}$ observe: 'in no branch of the history of science or medicine has there been less interpretive consensus'. Certainly during the 1980s there was an uneasy relationship between historians and psychiatrists. For both sides there were positive and negative aspects to the relationship.

\section{Positive factors in the involvement of historians for psychiatrists}

It was undoubtedly a healthy development when the new revisionist histories challenged the often complacent accounts by psychiatrists of their past. They undermined the 'Whiggish' narrative of benign progress and the notion of the 'Great Man' who improves the lot of the

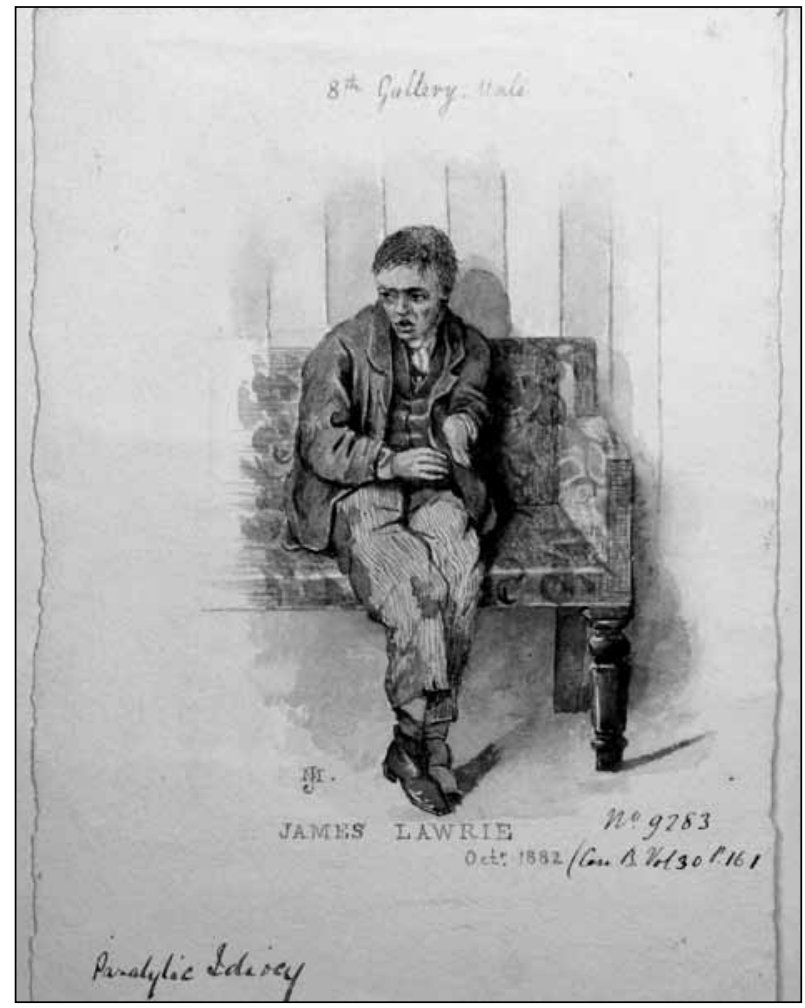

FIGURE I John Myles drawing 3, James Lawrie, (GDI6 Box 15).

mad by his sole efforts. These new histories held that the situation was much more complex and demonstrated the importance of social, cultural and political factors. Historians taught that interpretation of primary sources must be done with great care; clinicians should not just extract passages from archives without considering the context of the text: Who wrote it? Why was it written? How did it relate to the culture of the time? Historians showed that language, in particular medical terminology, changes over time. One cannot assume that physicians writing 100 years ago used medical terms in precisely the same way as they do now.

\section{Negative factors for psychiatrists}

From the psychiatrist's point of view, historians lacked a knowledge of mental illness and often had no first-hand experience of it. As a result they seemed too willing to see it as merely a social construct. For psychiatrists, working with disturbed and distressed patients, this seemed a glib and negligent attitude. Historians also had a tendency to speak in general terms rather than look at the particular: for example, many historians talked about 'madness' rather than specific conditions.

For psychiatrists, it was sometimes hard to take the often negative portrayal of their profession by historians. Psychiatrists were cast as agents of social control, helping the state to remove its discontents; they were insensitive brutes, more interested in doping their patients with medication than listening to their concerns. Psychiatrists were further irked when it seemed that, in 


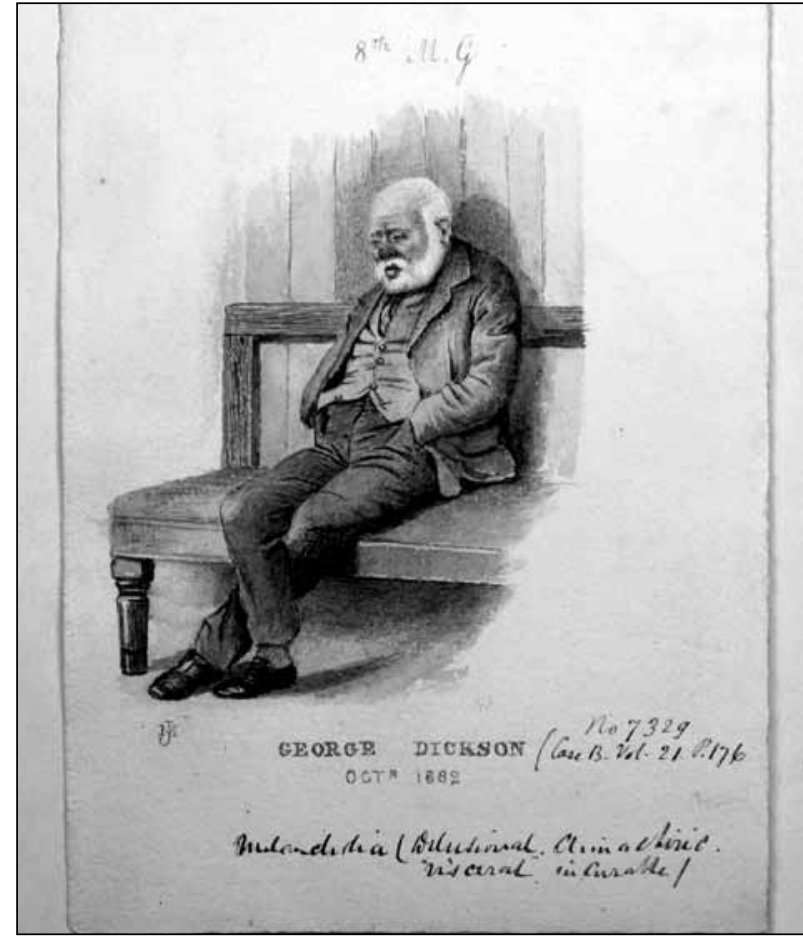

FIGURE 2 John Myles drawing I, George Dickson (GDI6 Box 15).

contrast, historians were presenting themselves as entirely 'neutral', free from prejudice or any personal agenda. If psychiatrists were a product of social and cultural forces, did this not equally apply to historians, a point conceded by some scholars?

There was also a perception that historians were hostile to non-historians writing about history, which was understandable, given that historians had spent many years at university learning their craft. However, Jacalyn Duffin ${ }^{7}$ in her review of clinician-historians concluded: "the "genre" of clinician history did not really exist separate from the rest of medical history, except as a "straw man"... a construct of would-be detractors who marshal it in service of a useless turf war over who should be writing history'. ${ }^{8}$ Micale and Porter have also dismissed the notion of the clinician-historian producing inferior work and have pointed to the examples of Henri Ellenberger and George Rosen. ${ }^{5}$

Psychiatrists sometimes felt that historians employed technical, professional language in their writings in order to keep outsiders out and to give the impression that the practice of history was a mysterious and arcane art. Although he was writing about English studies, John Sutherland's ${ }^{9}$ comments could also apply to history:

Over the past 30 years, the subject has been progressively dominated by hierophants with a hieratic, in-group jargon incomprehensible to the non-initiated. It certifies high seriousness... it was testingly difficult to master. That, one sometimes suspected was its point. ${ }^{10}$

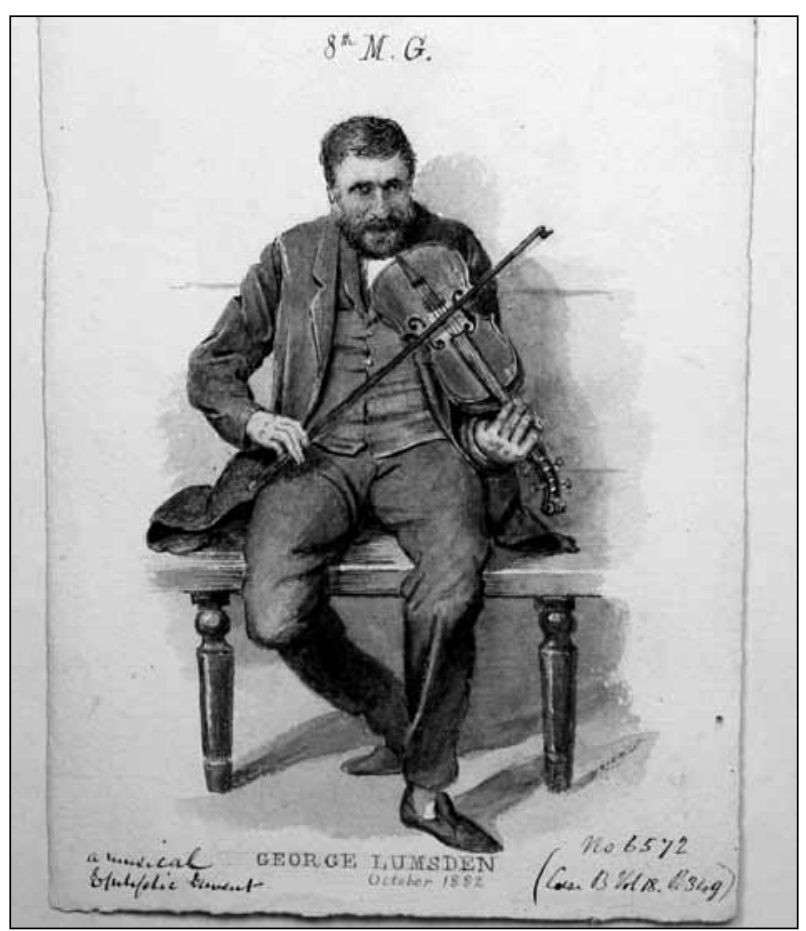

FIGURE 3 John Myles drawing 6, George Lumsden, (GDI6 Box 15).

Psychiatrists had been accused of the 'professionalisation' of their trade. Their claim to be the sole agency with expertise in the treatment of mental disorder, their journals, their institutions, their conferring of qualifications: all were seen as a way of putting them above and beyond lay people. But, they countered, could not the same be said of historians: that the professionalisation of their activities was a means of keeping others out?

\section{Positive factors of involvement of psychiatrists, for} historians

It was hoped by psychiatrists that historians would be interested in a dialogue with clinicians, as they had firsthand knowledge of the world of psychiatry. They encountered the mentally ill on a daily basis and they represented a potentially rich source of oral history. There was also the hope that a dialogue with psychiatrists might serve to demystify them: historians would see that psychiatrists were perfectly ordinary people and not the ogres of mythology. At least that was the hope.

\section{Negative factors for historians}

For historians, it seemed that many psychiatrists were unreflective about the nature of psychiatry. They tended to assume the virtue of the clinician and the lofty, humanitarian aims of their work. Psychiatrists also seemed to assume the validity of psychiatric diagnosis and terminology and to apply it to different historical eras and cultures. They assumed that mental illness was unchanging over time and place and did not take into account the cultural context. Psychiatrists, and indeed all 
clinicians, seemed to have a worrying fondness for retrospective diagnosis. Historical figures were subjected to modern-day classification and a diagnosis made, which, in the eyes of the doctor, explained their actions." As the historian Daniel Pick ${ }^{12}$ wrote of this period: '... the claims of psychiatry to be scientific and objective were reappraised. How far, it was asked, were psychiatric diagnoses and treatments shaped by unacknowledged culturally determined considerations of gender, skincolour, age, class, or ethic provenance?'13

\section{PERSONAL ACCOUNT}

In the preface to Darwin's Metaphor, the historian, Robert MYoung ${ }^{14}$ wrote:

Some of my remarks... may be taken as inappropriate, too personal, gossip (merely 'a personal perspective' - not my phrase). They have not been written idly. It is part of my position that the social relations of scholarship include the social relations in scholarship... The substance of knowledge is the work that gets written, published, and taken up. This is determined by all sorts of processes in the culture: those that shape the questions which it occurs to people to ask; those that determine what research to fund... those that constrain what people feel able to write up and submit to... 'peer review'; those that result in refereeing, revision, and - finally - publication. ${ }^{15}$

Young points out that standard accounts of scholarly activity tend to ignore the social context in which work is produced and how individuals influence and shape the process. In my experience, I have undoubtedly been influenced by the culture in which I trained, but also by the people I met along the way.

I studied medicine at Glasgow in the late 1970s. The radical Glasgow psychiatrist, RD Laing was very much a cultural force at this time. His books, steeped in literature and philosophy, were a demonstration that the humanities could contribute to the understanding of mental illness. He seemed to be an attractive role model: the psychiatrist as hip, social commentator, who also possessed a rare empathy for the mentally troubled. Laing favoured an existential approach, which attempted to see the patient's predicament through their eyes: to enter the patient's world. Attractive as it was, Laing's work also raised disturbing questions, especially for the would-be psychiatrist. Were psychiatrists agents of social control? Were they there at the bidding of the state to stifle originality and nonconformity? These themes were to be echoed by revisionist historians some years later, and Laing, as well as the libertarian psychiatrist Thomas Szasz, and the sociologist Erving Goffman, have been credited with stimulating such research. ${ }^{5}$
After qualifying I trained in psychiatry at the Royal Edinburgh Hospital.At that time the M Phil postgraduate course involved a series of lectures by staff from the university department of psychiatry. Professor Henry Walton was well versed in European philosophy and brought this perspective to psychiatry. Tom Walmsley, who wrote the chapter on the history of psychiatry in the Edinburgh Companion to Psychiatric Studies, ${ }^{16}$ gave lectures which not only demonstrated his encyclopaedic knowledge of history, but also covered the views of Kierkegaard, Sartre, Darwin and Cervantes. Like Laing, he showed the benefits that an engagement with the humanities could bring to the understanding of mental disturbance and the practice of psychiatry. He provided another role model, this time the psychiatrist as intellectual and wit.

Later I began historical research on the Royal Edinburgh Asylum, as the hospital was known in the nineteenth century. I was very fortunate that the archivist at the Lothian Health Services Archive was Dr Mike Barfoot, who was also an eminent historian of psychiatry. He provided an unofficial apprenticeship in the study of history and demonstrated how to approach historical records and the complexities of interpreting them. This he related to the secondary literature and showed that it was important to place one's work in the context of what other historians had written.

\section{RESEARCH}

In this section, l'll look at how the historical research I have undertaken has influenced my clinical practice and, likewise, how being a psychiatrist has influenced my choice of research topics. The main areas of historical research that I have pursued are: analysis of asylum case notes; studying the patients' perspective on madness and psychiatry; and biographies of clinicians and patients.

\section{Case notes}

Like other would-be historian-psychiatrists, I began my historical research by analysing asylum case notes. This type of research seemed attractive because it dealt with the familiar: clinical symptoms. Psychiatrists felt, not unreasonably, that they had some expertise in this area. In addition it enabled psychiatrists to test the theories of the revisionist historians. Where they dealt with the 'big picture' which portrayed the asylum as a 'dumping ground' for society's discontents, clinicians were looking at individual patients in specific institutions. Of course, both perspectives are important. Individual studies should help to modify the 'grand synthesis' approaches, while they, in turn, have to be related to the larger context.

In my paper entitled, Madness in Victorian Edinburgh: A Study of Patients Admitted to the Royal Edinburgh Asylum, $1873-1908,{ }^{17} \mathrm{I}$ looked at admissions to the institution 
during the period when Thomas Clouston was Medical Superintendent. Highly regarded among his peers, he was an editor of the Journal of Mental Science, the author of a standard Victorian textbook on mental disease and, increasingly in his later years, an outspoken commentator on the state of Victorian society. A total of I, I6I case notes from patients admitted between 1873 and 1908 were analysed. It was found that age, sex and social class were representative of the wider society. The majority of patients had recognisable psychiatric illnesses. Even taking into consideration that this was a study of mental disturbance from a different era and culture, the symptoms described in the case notes were familiar. Thus the asylum could not be seen as a 'dumping ground' for society's discontents. Reading the case notes however, one was also struck by how much the supposedly 'scientific' language of the clinicians reflected the values and assumptions of Victorian society; at times, it was very judgmental. This made me pause and consider how the language of present-day psychiatric discourse contains assumptions and prejudices. Such biases seem more obvious when one reads nineteenth century case notes which reflect a different world. It is less obvious in our own clinical writing as we are embedded in the culture of our day and may not even be aware of the values we are applying.

\section{The patient's perspective}

However, the case note study told only one side of the story: the view from clinicians. I wanted to see how patients viewed their time in the asylum and their experience of madness. Fortunately, the Royal Edinburgh Asylum case notes contained many letters by inmates. The Scottish lunacy laws enabled staff to hold back patient correspondence if they deemed it was not fit for the outside world. Such letters were often appended to case notes and during Clouston's period of office over I,000 were filed. In Life in the Asylum: Patients' Letters from Morningside, 1873-1908, ${ }^{18} \mathrm{I}$ examined this remarkable collection. The letters vividly portray what it was like to be a patient and, though they were written by inmates of a Victorian institution, many of the themes apply to the experience of today's patients.

The letters highlighted many aspects: the tedium of institutional life; the impact of being detained against one's will and the consequent lack of liberty; the experience of living with a large number of other inmates, who were usually complete strangers; and the relationship between staff and patients. Such accounts are very enlightening for clinicians to read and makes one appreciate the patient's situation more fully. For example, William B. wrote about being constantly monitored in the asylum:

I challenge the whole attitude of mind of $\mathrm{Dr}$ Clouston in his estimate of the insanity of those in his charge. I have spoken already of the inadequacy of the time of actual personal knowledge and observation. But no less dangerous is their mental attitude or process of proof. They are always watching for evidence to justify detention. All your rational conduct, all the evidence of sanity makes no impression on their mind, is quickly or immediately forgotten. While the slightest mistake, the slightest momentary forgetfulness, the slightest ebullition of temper is carefully noted, always treasured up and will be remembered against you for months or even years afterwards. I say this life in an asylum is an immense strain upon your mind.

In this passage, William B. anticipates the work of Erving Goffman, ${ }^{19}$ who examined institutional life in his classic book, Asylums, and demonstrated that, just by being in a mental hospital, a patient's behaviour was perceived by staff in a certain way.

The patients I have studied varied in their response to the asylum. John Gilmour ${ }^{20}$ and Mary Coutts ${ }^{21}$ railed against what they perceived as their wrongful confinement, while Christian Watt ${ }^{22}$ saw the asylum as a haven from the outside world. Other like John Willis Mason $^{23}$ alternated between hailing the asylum and vilifying it.

\section{Biography}

Biographies of clinicians allow one to compare and contrast one's own practice with those who went before. Having written about Victorian clinicians, such as Thomas Clouston, John Bucknill and Daniel Hack Tuke, I returned to RD Laing who had first inspired me as a student. ${ }^{24}$ Laing is intriguing because he was immersed in the humanities and he brought this to the theory and practice of psychiatry. I was interested in the patient perspective, which made Laing's existential approach appealing because it involved an attempt to see the patient's predicament through his or her eyes. The Laing archive of his personal papers contains his extensive clinical notes in which he recorded verbatim his interviews with patients. This allows us to compare what he wrote with what he did in clinical practice.

Laing's clinical notes demonstrate that he was heavily influenced by the psychiatric culture of his time and how, as he gained experience, he modified his approach. In his interviews with his most famous patient, Edith, who was to become 'Julie' in The Divided Self, ${ }^{25}$ we see him initially adopt the psychoanalytically-based 'direct analysis', in which the therapist seeks to enter the patient's inner world, supposedly by adopting the language of the unconscious. This extract (with Laing's notes in parenthesis) is illustrative: ${ }^{24}$

EDITH l've no tongue. I've a tongue but it's not my actual tongue. 
LAING You have a tongue in your mouth anyway. EDITHYes, l've a tongue in my mouth, but it's not my actual tongue. l've no actual tongue.

(I was a bit lost at this point. ? tongue = nipple [= penis]. Tongue $=$ nipple seemed from yesterday to be more important. She had apparently lost her 'tongue' and hence 'couldn't speak'. Had she been weaned? Bitten off and swallowed nipple? How lost it? Castrated? but what level of regression to work on?)

LAING Well I'm glad to hear that in a way. One tongue in your mouth is enough for anyone.

EDITH l've a tongue in my mouth (it peeks out from between her teeth rather coyly).

LAING You won't lose that tongue. The other tongue never really belonged to you anyway. You must have pinched it from somewhere... You've at least ten nipples anyway...

This conversation seems bizarre to us today, but, once again, it demonstrates how clinicians are influenced by the theories of their time, and it should make us more sceptical of our own ideas about mental illness.

The response to Laing among present-day psychiatrists is quite often hostile, especially from establishment figures in the Royal College of Psychiatrists. ${ }^{26}$ This reveals the changing perceptions of historical figures. Where a previous generation of psychiatrists, like Anthony Clare, cited Laing's The Divided Self as inspiring them to become psychiatrists, many today dismiss him. He does not fit with the narrative of bioscientific progress that modern psychiatry wants to tell about itself.

\section{CONCLUDING REMARKS}

Several authors have noted similarities in the goals of historians and psychiatrists. For example, the medical historian, Andrea Tone ${ }^{27}$ has argued that historians and psychiatrists have much in common. Both try to understand the struggles of their subjects, both 'spend an inordinate amount of time studying people, tracking clues, and piecing together fragmentary evidence to make sense of a situation'. In a previous paper, I also pointed to the similarities between the work of the psychiatrist and the historian: both endeavour to construct a meaningful narrative out of the disorder of human experience. ${ }^{28}$ The argument has been taken further.The psychiatrist-historian, Gary Belkin ${ }^{29}$ writes: 'If all physicians are historians, psychiatrists are the elite of the profession. For us, attention to history is particularly keen. Patient histories are perhaps more crucial and exhaustively detailed here than in other specialities... Psychiatrists... need to be open and careful about interpretation of history. They attend to the problems of the distortion of memory, the instability of what counts as facts...'

Over the years I have valued collaborating with historians and have appreciated the ongoing dialogue between the two disciplines. However, it does seem that this dialogue is less in evidence today. There are several recent edited volumes on the history of psychiatry, whose contributors are exclusively historians. In parallel, a leading paper $^{30}$ in the British Journal of Psychiatry, celebrating its bicentenary in 2012, gave a 'Whiggish' account of the progress of psychiatry and made little reference to the last 30 years of historical scholarship. In the past, the journal featured papers on the history of psychiatry, but this is now a rarity. In part this is because of the advent of the journal, History of Psychiatry. This journal was set up with the laudable aim of improving the standard of scholarship. One unforeseen consequence is that only a certain number of psychiatrists read the journal and the history of psychiatry has lost the much larger audience afforded by the British Journal of Psychiatry. Another reason for the lack of articles on history in the journal is psychiatry's current image of itself as primarily a neuroscientific discipline. ${ }^{30}$

However not all psychiatrists see themselves as neuroscientists. ${ }^{31}$ Tone, in her interviews with psychiatrists concluded: 'few psychiatrists would identify themselves as technicians', and several described their work 'with a scepticism groomed by an appreciation of history'. From the historian's side, Matthew Smith ${ }^{32}$ has called for medical historians to engage directly with clinicians and described his encounters with psychiatrists. There are some positive signs. In recent years, social historians have increasingly examined psychiatric treatments and asylum case notes and this has brought them closer to the everyday experience of mental illness, while the work of clinician-historians like David Healy and Joel Braslow has been enthusiastically received by historians.

Both Glasgow and Edinburgh Universities now have medical humanities networks that aim to provide a forum for all interested disciplines. More specifically, at Edinburgh University the medical historian, Gayle Davis has set up a course entitled 'Madness and Society in Britain since c. 1830', which allows history undergraduates to discuss the subject with a psychiatrist. At the same university, another medical historian, Ivan Crozier, teaches a graduate seminar on the history of psychiatry that has been taken by history, psychology and psychiatry students. Outside Scotland there are similar developments, for example in Birmingham, Durham, Nottingham and London. An encouraging sign is that among history students, one of the most popular topics for a dissertation is the history of psychiatry. Another 
growth area is that of philosophy and psychiatry with, for example, the ever-expanding Oxford University Press series, 'International Perspectives in Philosophy and Psychiatry', which has attracted contributions from a wide range of disciplines, many of which adopt an historical perspective.

I have looked at the interplay between the study of history and clinical practice from a personal perspective. I think that studying history has made me more questioning of contemporary psychiatry theories and more aware of the patient's viewpoint. It has also made me aware of the enormous influence that culture exerts on how we conceive of mental illness and how we think it should be alleviated.

\section{REFERENCES}

I Warner J H. The humanising power of medical history: responses to biomedicine in the 20th century United States. Med Humanit 20I I; 37:9I-6. http://dx.doi.org/ I0.1 I36/medhum-20 I I-0I0034

2 Foucault M. Madness and civilisation: a history of insanity in the age of reason (trans. R Howard). London:Tavistock; 1965.

3 Scull A. Museums of madness: the social organisation of insanity in nineteenth century England. Harmondsworth: Penguin Books; 1979.

4 Bynum WF, Porter R, Shepherd M (editors). The anatomy of madness: essays in the history of madness. Volumes I-3. London: Tavistock Publications; 1985.

5 Micale M, Porter R (editors). Discovering the history of psychiatry. Oxford: Oxford University Press; 1994

6 Micale M, Porter R (editors). Discovering the history of psychiatry. Oxford: Oxford University Press; 1994. pp. 10-II.

7 Duffin J (editor). Clio in the clinic: doctors' stories of using history in medical practice. Toronto: University of Toronto Press; 2005.

8 Duffin J (editor). Clio in the clinic: doctors' stories of using history in medical practice. Toronto: University of Toronto Press; 2005. p. 6.

9 Sutherland J. Critical Faculty. The New Statesman. 2012; 18 July; 47

10 Sutherland J. Critical Faculty. The New Statesman. 20I2; 18 July; 47. p. 232.

II Beveridge A. Diagnosis of historical figures. J Med Biog 2004; 12:126-7.

12 Pick D. The pursuit of the nazi mind. Hitler, Hess and the analysts Oxford: Oxford University Press; 2012.

I3 Pick D. The pursuit of the nazi mind. Hitler, Hess and the analysts. Oxford: Oxford University Press; 2012. p. 232.

14 Young RM. Darwin's metaphor: nature's place in Victorian culture. Cambridge: Cambridge University Press; 1985.

I5 Young RM. Darwin's metaphor: nature's place in Victorian culture. Cambridge: Cambridge University Press; 1985. p. xxiii-xiv.

16 Walmsley T. Historical introduction. In: Kendell RE, Zealley AK (editors). Edinburgh companion to psychiatric studies. 4th ed. Edinburgh: Churchill Livingstone; 1988. p. I-II.

17 Beveridge A. Madness in Victorian Edinburgh: a study of patients admitted to the Royal Edinburgh Asylum under Thomas Clouston, 1874-1908. Parts I \& 2. Hist Psychiatry 1995; 6:21-54; 133-56. http://dx.doi.org/I0.I I77/0957/54X9500602I02

18 Beveridge A. Life in the asylum: patients' letters from Morningside, 1873-1908. Hist Psychiatry 1998; 9:431-69. http://dx.doi. org/10.1 I77/0957/54X9800903602

\section{Figures}

Drawings of patients by John Myles, probably commissioned by $\mathrm{Dr}$ Thomas Clouston, Physician Superintendent of the Royal Edinburgh Hospital. Courtesy of Lothian Health Services Archive, Edinburgh University Library.

19 Goffman E. Asylums. Essays on the social situation of mental patients and other inmates. New York:Anchor Books; 196I.

20 Beveridge A, Williams M. Inside 'The Lunatic Manufacturing Company': the persecuted world of John Gilmour. Hist Psychiatry 2002; I3: I 9-49. http://dx.doi.org/ I0. I I77/0957| 54X0201304902

2I Beveridge A. Britain's Siberia: Mary Coutts's account of the asylum system. J R Coll Physicians Edinb 2005; 35: I75-8I.

22 Beveridge A, Watson F. The psychiatrist, the historian and the Christian Watt papers. Hist Psychiatry 2006; 17:205-2I. http://dx. doi.org/I0.II77/0957I54X06058949

23 Barfoot M, Beveridge A. 'Our most notable inmate': John Willis Mason at the Royal Edinburgh Asylum, 1864-1901. Hist Psychiatry 1993; 4: I59-208. http://dx.doi.org/I0.II77/0957I54X930040I402

24 Beveridge A. Portrait of the psychiatrist as a young man. The early writing and work of RD Laing, 1927-1960. Oxford: Oxford University Press; 201 I. http://dx.doi.org/10.1093/med/9780199583577.001.000 I

25 Laing RD. The divided self. An existential study in sanity and madness. London:Tavistock; 1960.

26 Beveridge A. RD Laing revisited. Psychiatric Bulletin 1998; 22:452-6. http://dx.doi.org//0.1 192/pb.22.7.452

27 Tone A. Listening to the past: history, psychiatry and anxiety. Can J Psychiatry 2005; 50:373-80.

28 Beveridge A. Relevance of the history of psychiatry to practising clinicians. Adv Psychiatr Treat 1999; 5:46-52. http://dx.doi.org// 0.1 192/ apt.5.I.46

29 Belkin GS. We are all historians: thoughts about doing psychiatry In: Duffin J (editor). Clio in the clinic: doctors' stories of using history in medical practice. Toronto: University of Toronto Press; 2005. PP. 236-47.

30 Tyrer P, Craddock N. The bicentennial volume of The British Journal of Psychiatry: the winding pathway of mental science. $\mathrm{Br} J$ Psychiatry 2012; 200: I-4. http://dx.doi.org/ I0.1 I 92/bjp.bp. I I . I06377

3I Mulder RT.Why study the history of psychiatry? Aust N Z J Psychiatry 1993; 27:556-9. http://dx.doi.org// 0.3109/000486793090758I7

32 Smith M. Mixing with medics. Soc Hist Med 20I I; 24: I42-50. http:// dx.doi.org/I0.1093/shm/hkq I I6 